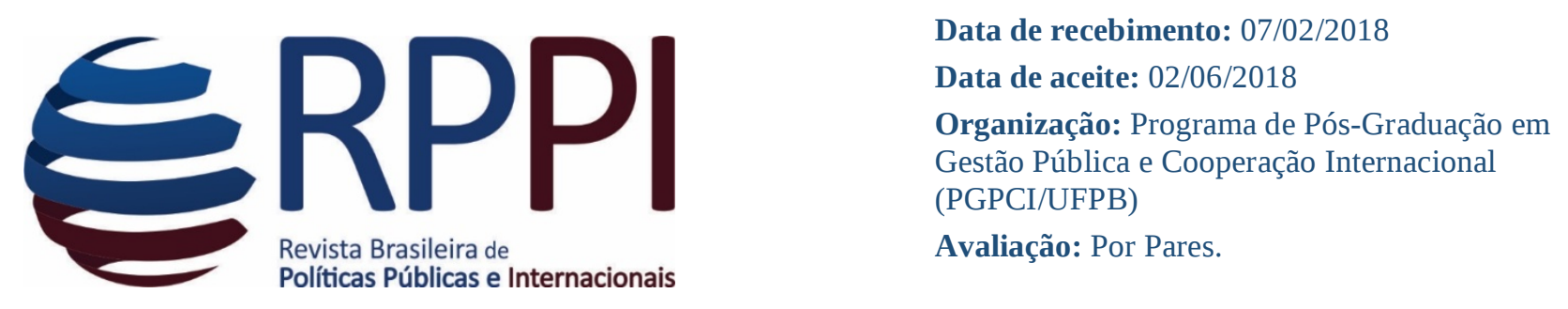

\title{
A Economia Política Internacional e a Agenda Ambiental: como o tratado de cooperação amazônico está inserido na relação centro-periferia?
}

\section{The International Political Economy and the Environmental agenda: how is the amazon cooperation treaty inserted in the center-periphery relationship?}

\author{
Murilo Mesquita \\ Doutorando em Ciência Política pelo Programa de Pós-Graduação em Ciência Política pela \\ Universidade Federal de Pernambuco (UFPE). \\ E-mail: murilo_mesquita@hotmail.com.
}

Monique de Medeiros Linhares

Mestranda em Relações Internacionais pelo Programa de Pós-Graduação em Relações Internacionais pela Universidade Estadual da Paraíba (UEPB).

E-mail: monique_medeiros@outlook.com.br

Luiza Bandeira de Mello Vasconcelos

Graduanda em Relações Internacionais na Universidade Federal da Paraíba (UFPB).

E-mail: luizabandeira.m@gmail.com

Bianca Mendes Araújo

Graduanda em Relações Internacionais na Universidade Federal da Paraíba (UFPB).

E-mail: mendesaraujobianca@gmail.com

Resumo: O tema do trabalho é a Economia Política Internacional (EPI) e a agenda ambiental por trás de regimes de cooperação. Tem a pergunta-problema: como o Tratado de Cooperação Amazônico (TCA) está inserido na relação centro e periferia? Seu objetivo geral é analisar o TCA na relação Centro-Periferia e seus objetivos específicos (i) apresentar a inserção da agenda ambiental nos estudos da EPI; (ii) identificar as relações centro-periferia na Política Ambiental Global; e (iii) examinar o Tratado de Cooperação Amazônico. No desenho de pesquisa, o argumento central é: o TCA é uma resposta dos países amazônicos aos interesses do Centro. Usa-se uma metodologia qualitativa, com método de análise de conteúdo e de discurso. Ao fim é possível corroborar o argumento central da pesquisa

Palavras-chave: Economia Política Internacional; Meio Ambiente; Tratado de Cooperação Amazônica; Centro-Periferia. 


\begin{abstract}
The theme of the work is the International Political Economy (IPE) and the environmental agenda behind the cooperation's regime. There is the question: how is the Amazon Cooperation Treaty (ACT) inserted in the relationship between the center and the periphery? Its general objective is to analyze the ACT in the Center-Periphery relationship and its specific objectives (i) present the insertion of the environmental agenda in the studies of the EPI; (ii) identify the center-periphery relations in the Global Environmental Policy; and (iii) to examine the Amazon Cooperation Treaty. In the research project, the central argument is: the ACT is a response of the Amazonian countries to the interests of the Center. A qualitative methodology is used, with a method of content and discourse analysis. In the end, it is possible to corroborate the central argument of the research.
\end{abstract}

Keywords: International Political Economy; Environment; Amazon Cooperation Treaty; CenterPeriphery.

\title{
1. Introdução
}

O presente trabalho tem como tema a relação entre a Economia Política Internacional (EPI) e a agenda ambiental por trás do Tratado de Cooperação Amazônica (TCA). Nesse estudo utiliza-se uma perspectiva crítica para responder a seguinte questão: como o Tratado de Cooperação Amazônico está inserido na relação Centro-Periferia? Essa pergunta busca refletir sobre a situação da EPI no tocante ao desenvolvimento do capitalismo e suas consequências para o meio ambiente, especialmente na região da Amazônia.

Em pleno século XXI, as consequências do desenvolvimento capitalista são cada vez mais alarmantes para o meio ambiente, de modo que arranjos cooperativos que ensejam um embedded liberalism não fornecem uma sustentação apropriada para políticas públicas ambientais que sustentam um discurso de desenvolvimento sustentável. Nesse sentido, olhar o TCA desde uma perspectiva crítica permite observar como acordos internacionais podem surtir políticas públicas de viés sustentável.

Assim, o objetivo geral do trabalho é analisar o TCA na relação Centro-Periferia. Para tanto, são objetivos específicos (i) apresentar a inserção da agenda ambiental no campo de estudo da Economia Política Internacional; (ii) identificar as relações Centro-Periferia na Política Ambiental Global; e (iii) examinar o Tratado de Cooperação Amazônico. O desenho de pesquisa tem o seguinte argumento central: o TCA é uma resposta dos países amazônicos aos interesses do Centro

Revista Brasileira de Políticas Públicas e Internacionais, v.3, n.2, Dezembro/2018, pp. 100-124. 
MESQUITA, Murilo; LINHARES, M. de M.; VASCONCELOS, L. M. B.; ARAÚJO, B. M. A Economia Política Internacional e a Agenda Ambiental: como o tratado de cooperação amazônico está inserido na relação centro-periferia?

capitalista. Desde uma cultura metodológica qualitativa, a pesquisa é desenhada como um estudo de caso e recorre às técnicas de análise do discurso e de conteúdo, executados em cima de pesquisa bibliográfica e documental.

O trabalho está dividido em três partes: a primeira apresenta uma breve introdução à Economia Política Internacional e à inserção da agenda ambiental nesses estudos. Na segunda, a temática ambiental é salientada de modo a tornar cristalino o objeto de estudo da pesquisa, o TCA. Na terceira, o TCA é examinado para compreender suas fragilidades no tocante o ensejo de uma política pública que não fornece alternativas ao avanço do capitalismo no meio ambiente

\section{Os estudos de EPI e a inserção da temática ambiental}

Essa seção tem como objetivo apresentar a Economia Política Internacional (EPI) e a inserção da agenda ambiental. A EPI, como "uma mistura eclética de métodos analíticos e perspectivas teóricas” (Gilpin, 2002, pp. 25-26), aglutina economia e política, para investigar de que forma o Estado, a política e os processos políticos subjacentes a eles influenciam a produção e a distribuição de riquezas.

Dessa forma, o método de estudo da área tem um alcance que investiga criticamente as mudanças na estrutura histórica das sociedades humanas, por isso seu escopo atinge as ciências sociais como um todo (Der Pijl, 2015). Nesse sentido, seu objetivo é “identificar as características que seriam mais importantes para o funcionamento do capitalismo” (Hunt \& Lautzenheisser, 2013, p. 1).

Esse objetivo está diretamente vinculado à compreensão crítica que sustenta os estudos de EPI. Nestes, o capitalismo é observado como uma improvável formação social, permeada por conflitos e contradições, que se encontram em permanente instabilidade (Streeck, 2016). Com esses conflitos e contradições, a EPI interpreta a sociedade capitalista a partir da expansão do mercado e do risco (Der Pijl, 2015).

Quando esse olhar se debruça sobre a relação Centro-Periferia do sistema de produção capitalista, observa-se que o Centro é identificado com as economias em que técnicas capitalistas de produção são mais bem desenvolvidas e aplicadas. A Periferia, por sua vez, constitui-se por economias cujas capacidades produtivas são relativamente atrasadas, porque imersas em relações comerciais desiguais (Rodriguez, 2009).

Revista Brasileira de Políticas Públicas e Internacionais, v.3, n.2, Dezembro/2018, pp. 100-124. 
MESQUITA, Murilo; LINHARES, M. de M.; VASCONCELOS, L. M. B.; ARAÚJO, B. M. A Economia Política Internacional e a Agenda Ambiental: como o tratado de cooperação amazônico está inserido na relação centro-periferia?

Não obstante essa conceituação inicial, as noções de Centro e Periferia se tornam mais complexas. Na Periferia, esse atraso é relativo aos setores que se misturam aos interesses do Centro, ou seja, o progresso tecnológico ocorre, mas de forma parcial e conforme a demanda dos grandes centros industriais. Quando o progresso ocorre de forma retardada e em função das demandas externas, termina por privilegiar setores específicos que não demandam um alto nível de capital humano.

Ao se constituir dessa forma, a estrutura produtiva da Periferia adquire duas características: a (i) especialização e (ii) heterogeneidade. Ou seja, setores específicos alcançam níveis altos de produtividade enquanto outros mantêm níveis de produção consideravelmente inferiores. Por seu turno, o Centro capitalista é caracterizado com uma estrutura produtiva (i) diversificada e (ii) homogênea (Rodriguez, 2009).

Nesse sentido, a relação Centro-Periferia é acompanhada pela relação desenvolvimentosubdesenvolvimento, no qual o intercâmbio comercial ou as trocas desiguais de produção conformam e reproduzem a estrutura produtiva diversificada e homogeneizada, de um lado, e especializada e heterogeneizada, de outro (Rodriguez, 2009).

Nas palavras de Furtado (2009, p. 161),

o efeito do impacto da expansão capitalista sobre as estruturas arcaicas variou de região para região, ao sabor de circunstâncias locais, do tipo de penetração capitalista e da intensidade desta. Contudo, a resultante foi quase sempre a criação de estruturas híbridas, uma parte das quais tendia a comportar-se como um sistema capitalista, a outra, a manter-se como dentro da estrutura preexistente. Esse tipo de economia dualista constitui, especificamente, o fenômeno no subdesenvolvimento contemporâneo.

Dada essas características, é possível observar que o sistema mundial tende a favorecer os produtos industrializados do Centro, em contraposição aos produtos primários, sem valor agregado, da Periferia. A deterioração dos termos de troca faz com que o mercado internacional privilegie desenvolvimento no Centro, à medida que o subdesenvolvimento é administrado para gerar mais riquezas para o mesmo (Oliveira, 2007).

Com esse desenho da economia internacional, a privilegiar os interesses dos países centrais, foi necessário um levante dos países da Periferia na luta pelo desenvolvimento para Revista Brasileira de Políticas Públicas e Internacionais, v.3, n.2, Dezembro/2018, pp. 100-124. 
MESQUITA, Murilo; LINHARES, M. de M.; VASCONCELOS, L. M. B.; ARAÚJO, B. M. A Economia Política Internacional e a Agenda Ambiental: como o tratado de cooperação amazônico está inserido na relação centro-periferia?

colocar em questão todo esse processo (Oliveira, 2007). Por volta da década de 1970 e 1980, uma nova agenda começa a emergir dentro da luta pelo desenvolvimento e dentro dos estudos da EPI - a questão ambiental. Desse modo, a agenda ambiental lança uma pauta pela sustentabilidade a ponto de fazer repensar os caminhos tradicionais ao desenvolvimento (Clapp \& Helleiner, 2012).

\subsection{O meio ambiente e a Economia Política Internacional}

Essa subseção tem como objetivo apresentar a inserção da agenda ambiental no campo de estudo da EPI. A Economia Política Internacional e Meio Ambiente surge quando os problemas ambientais passam a não serem observados mais como exclusivos aos Estados. Ao não respeitarem as fronteiras nacionais, a crise ecológica passa a ser identificada como o maior perigo, aquele que, diferentemente da crise financeira, "não tem solução nos marcos do sistema” (Löwy, 2013, p. 80, grifo do autor).

Assim, na década de 1970, a EPI vem a sofrer forte pressão por uma nova agenda política. Através da barganha pelo desenvolvimento sustentável, com pesquisas a focar desde a cooperação ambiental até às dinâmicas desiguais do capitalismo e suas consequências no meio ambiente, a agenda ambiental passou a ser incorporada cada vez mais pelos fóruns internacionais (Clapp \& Helleiner, 2012).

Nesse momento, a temática ambiental ao assumir uma dimensão transnacional envolve Estados, organizações internacionais e não-governamentais, corporações e demais grupos de pressão. Para Young (apud Chasek, Downie \& Brown, 2013), essa temática, devido seu alcance, pode ser agrupada sob quatro environment-issues que podem ser observadas na Tabela 1:

Tabela 1: Environment-issues.

\begin{tabular}{ll}
\hline Categorias de problemas & Temática e alcance ambiental \\
Comuns & Recursos Naturais \\
Recursos naturais compartilhados & Sistemas físicos ou biológicos que envolve a jurisdição \\
& de dois ou mais países
\end{tabular}

Revista Brasileira de Políticas Públicas e Internacionais, v.3, n.2, Dezembro/2018, pp. 100-124. 
MESQUITA, Murilo; LINHARES, M. de M.; VASCONCELOS, L. M. B.; ARAÚJO, B. M. A Economia Política Internacional e a Agenda Ambiental: como o tratado de cooperação amazônico está inserido na relação centro-periferia?

\begin{tabular}{ll}
\hline Externalidades transfronteiriças & $\begin{array}{l}\text { Porosidade fronteiriça de um único país, com } \\
\text { consequências transfronteiriças }\end{array}$ \\
Linked issues & Casos em que acordos sobre o meio ambiente afetam \\
& outras agendas e/ou regimes.
\end{tabular}

Fonte: Elaboração própria a partir de Chasek, Downie \& Brown, 2013

A partir deste quadro, a Amazônia pode ser enquadrada em todas estas categorias de problemas que envolvem a agenda ambiental. É um (i) problema comum, devido os recursos naturais que podem ser compartilhados. É um (ii) problema de recurso natural, pois envolve a jurisdição de vários países. É um (iii) problema de externalidade fronteiriça, devido a porosidade das fronteiras dos países que fazem parte da região amazônica. E, por fim, é um (iv) problema de linked issues, pois é uma área que reivindica a atuação e arranjos cooperativos que envolvem mais de um ator internacional.

Com essa percepção, a próxima seção observa como a agenda ambiental tem sido inserida na pauta de discussão das relações internacionais. Por isso, o argumento que segue aprofunda a inserção da agenda ambiental nos estudos de EPI ao trabalhar com o conceito de Política Ambiental Global. Da mesma forma, constrói uma estrutura de análise que permite alocar o Tratado de Cooperação Amazônica às relações centro-periferia da economia política internacional.

\section{As desigualdades na Política Ambiental Global}

Nesta seção o objetivo é identificar a relação Centro-Periferia na Política Ambiental Global (PAG). Nessa relação, a globalização é apresentada como um dos fatores a colocar o meio ambiente em decadência no mundo inteiro, pois acelera as desigualdades bem como as agressões ao meio ambiente (Harris, 2014; Kochtcheeva, 2014). Sendo assim, qual a relação entre a globalização e o meio ambiente a partir da PAG?

Antes de responder essa questão, a pesquisa compreende que a "globalização tem um aspecto inegavelmente material, na medida em que é possível identificar, por exemplo, fluxos de comércio, capital e pessoas em todo o globo” (Held \& Mcgrew, 2001, p. 12). Contudo, o atual fenômeno da globalização assume características de um projeto político-econômico neoliberal, em Revista Brasileira de Políticas Públicas e Internacionais, v.3, n.2, Dezembro/2018, pp. 100-124. 
MESQUITA, Murilo; LINHARES, M. de M.; VASCONCELOS, L. M. B.; ARAÚJO, B. M. A Economia Política Internacional e a Agenda Ambiental: como o tratado de cooperação amazônico está inserido na relação centro-periferia?

que são acirradas as mais variadas desigualdades entre os países. Esse fenômeno apresenta seu caráter mais perverso quando privilegia uma minoria, alinhada ao processo de produção e acumulação capitalista e exclui grande parcela da população mundial, localizada na Periferia do sistema internacional (Santos, M. 2001).

Por isso, essa globalização é a constituição de um sistema-mundo que tem o capitalismo mundializado como matriz de poder colonial, que constrói um sistema-mundo capitalista/modernopatriarcal/colonial (Wallernstein, 1974; Quijano, 2000; Grosfoguel, 2006). Nessa matriz, o capitalismo estrutura um projeto de globalização “perverso”, em que a exclusão é o outro lado da moeda da expansão capitalista (Santos, M. 2001).

Nessa matriz, apesar da possibilidade de aproximação entre os Estados, a globalização econômica produz notório efeito negativo no meio ambiente e, por extensão, nas políticas relacionadas à proteção ambiental. Por isso, o papel que a política desempenha nas questões ambientais, sejam elas dentro ou entre os países, não pode ser subestimado (Harris, 2014; Kochtcheeva, 2014).

Muitas vezes, a capacidade de responder à crise econômica e ambiental é posta à disposição dos Estados e outros atores não-estatais como organizações intergovernamentais, organizações não-governamentais (ONG's) e empresas. A atuação desses atores se faz a partir de processos de negociação e tomadas de decisão para a implementação de políticas públicas que possam priorizar a proteção ambiental (Harris, 2014).

É a partir disso que são formuladas as políticas ambientais globais que buscam reforçar a compreensão e a solução para as mudanças ambientais. Essas políticas fornecem uma base de conhecimento que promove novas relações "ambientalmente sustentáveis entre a humanidade e o mundo natural” (Harris, 2014, p. 2). Para tanto, reconhece-se (i) a natureza global das mudanças climáticas, (ii) a influência das questões políticas sob o meio ambiente e que (iii) tanto as causas, como as consequências da mudança ambiental global possuem duas esferas - a política e a econômica - que são fortemente influenciadas pela distribuição do poder dentro das relações internacionais.

A partir disso, o que é a política ambiental global? Essa política pode ser interpretada como as várias maneiras de, em diferentes lugares, alterar ou proteger o meio ambiente. Ou seja, são políticas ambientais implantadas ou aplicadas em diferentes localizações e problemáticas, cujo

Revista Brasileira de Políticas Públicas e Internacionais, v.3, n.2, Dezembro/2018, pp. 100-124. 
MESQUITA, Murilo; LINHARES, M. de M.; VASCONCELOS, L. M. B.; ARAÚJO, B. M. A Economia Política Internacional e a Agenda Ambiental: como o tratado de cooperação amazônico está inserido na relação centro-periferia?

objetivo é gerar resultados que alteram ou protegem o meio ambiente. Dessa forma, representa também um campo de pesquisa e estudo. Nesse sentido, “o ambiente das políticas ambientais globais não é sobre o ambiente construído per si, [mas] sobre a administração do ambiente natural” (Harris, 2014, p. 4). Isso significa que a administração do ambiente global implica a necessidade de que atores estatais e não-estatais cooperem em prol de um futuro ambientalmente sustentável.

Assim, a PAG busca incluir os quatro tipos de problemas ambientais referenciados na Tabela 1 às conferências internacionais, com o intuito de negociar medidas, arranjos cooperativos e mesmo tratados que possam ser capazes de mitigar algum problema ambiental. Sendo assim, são esforços que incluem observar a atuação de atores estatais e não-estatais para gerenciar recursos compartilhados em áreas naturais comuns ou a formulação e implementação de políticas internacionais de desenvolvimento sustentável que beneficiem países e apoiem um desenvolvimento econômico ambientalmente menos prejudicial (Harris, 2014). Desse modo, “a política das políticas ambientais globais é, na maioria das vezes, o processo pelo qual a constelação de interesses diferentes é representada (ou não) em ações que prejudicam o ambiente natural ou em esforços para protegê-lo” (Harris, 2014, p. 5).

Assim, pensar uma agenda para uma política ambiental global é uma tarefa complexa. Como as relações internacionais ainda são fortemente marcadas por relações de poder assimétricas, a criação de um consenso em torno de uma agenda ambiental se configura como um forte obstáculo. Sendo um dos principais obstáculos à essa agenda, a manutenção das relações Norte e Sul, na qual está constituído um Centro desenvolvido e uma Periferia subdesenvolvida ou em desenvolvimento. Disto posto, é válido expressar que a relação política entre Centro e Periferia não é algo novo. Ela decorre do período da Guerra Fria, quando, tangente ao conflito político ideológico entre EUA e URSS, um grupo de países formou, em 1955, a Conferência de Bandung.

A Conferência Asiática-africana, também conhecida como Conferência de Bandung, trouxe para a cena internacional Estados recém-saídos dos processos de descolonização e uma agenda política atrelada aos interesses do Terceiro Mundo. A Comunicação Final da Conferência Asiática-africana expressa seis pontos, (i) Cooperação Econômica, (ii) Cooperação Cultural, (iii) Direitos Humanos e Autodeterminação, (iv) Problemas dos Povos Dependentes, (v) Outros Problemas e (vi) Promoção da Paz Mundial e Cooperação (FINAL COMMUNIQUÉ OF THE

Revista Brasileira de Políticas Públicas e Internacionais, v.3, n.2, Dezembro/2018, pp. 100-124. 
MESQUITA, Murilo; LINHARES, M. de M.; VASCONCELOS, L. M. B.; ARAÚJO, B. M. A Economia Política Internacional e a Agenda Ambiental: como o tratado de cooperação amazônico está inserido na relação centro-periferia?

ASIAN-AFRICAN CONFERENCE, 2009), que convergem na formação do Movimento dos NãoAlinhados.

O resultado dessa conferência foi, então, a emergência do “Espírito de Bandung”, sintetizado em três princípios: (i) o não-alinhamento (que difere de neutralidade) e não aceitação da coerção à bipolaridade da Guerra Fria; (ii) a eliminação de todas as formas de racismo e colonialismo; e (iii) a modernização e o desenvolvimento dos países do Terceiro Mundo. "Esses princípios representam a rejeição da coerção e dominação que tinha caracterizado a maneira colonial/imperial de interação entre o Ocidente e Ásia-África” (Nesadurai, 2005, p. 10, tradução nossa).

Dentre esses, é a rejeição ao colonialismo e a ênfase ao desenvolvimento econômico que marcam a dualidade na relação Centro-Periferia (Joshi, 2014). Os países da Periferia buscavam uma nova ordem econômica internacional que possibilitasse o desenvolvimento e a autodeterminação, sem a dependência de uma economia primário-exportadora que perpetuasse as relações de dominação da divisão internacional do trabalho.

Em meio a esse contexto, a agenda ambiental começa a ser inserida nas Relações Internacionais. Em 1972, com a Declaração de Estocolmo, elaborada na Conferências das Nações Unidas para o Meio Ambiente Humano, observa-se o conflito Centro-Periferia. Nessa conferência, a preocupação-chave do Centro era prevenir que os recursos globais fossem drenados pelo crescimento econômico dos países em desenvolvimento e subdesenvolvidos. Na Periferia, a posição do Centro era vista como algo injusto e conveniente para a manutenção das relações de dependência, traduzido como um ambientalismo ocidental cuja pretensão era, em síntese, colonialista (Silva, 2013).

Nesse contexto, a reivindicação dos países da Periferia se deu pela responsabilidade histórica ambiental do Centro, que alcançou seu nível de industrialização às custas dos recursos naturais originários dos países periféricos. Nesses termos, o embate se deu entre a ideia de débito ecológico, que responsabilizava os países industrializados pela degradação ambiental versus o ambientalismo (Silva, 2013; Joshi, 2014).

\footnotetext{
${ }^{1}$ These principles represented a rejection of the coercion and dominance that had characterized the colonial/imperial mode of interaction between the west and Asia-Africa
}

Revista Brasileira de Políticas Públicas e Internacionais, v.3, n.2, Dezembro/2018, pp. 100-124. 
MESQUITA, Murilo; LINHARES, M. de M.; VASCONCELOS, L. M. B.; ARAÚJO, B. M. A Economia Política Internacional e a Agenda Ambiental: como o tratado de cooperação amazônico está inserido na relação centro-periferia?

Assim, com o embate Centro-Periferia em torno da agenda ambiental, buscou-se institucionalizar políticas ambientais a fim de garantir os interesses dos grupos de países em disputa. Historicamente, essa institucionalização ocorre a partir de três momentos: a Conferência de 1972, os Relatórios Brundtland de 1987 e a Conferência do Rio, em 1992, que solidifica a divisão Centro-Periferia e contextualiza a ligação entre os temas de meio ambiente e desenvolvimento econômico (Silva, 2013; Joshi, 2014).

No âmbito dessas da primeira convenção é possível enxergar os anseios à produção do Tratado de Cooperação Amazônica. Na próxima seção, o tratado é examinado a partir de uma análise de conteúdo e do discurso de modo a verificar se o mesmo pode ser configurado como uma resposta da Periferia ao ambientalismo do Centro.

\section{O Tratado de Cooperação Amazônico}

De acordo com um ponto de vista que atinge diferentes níveis de análise de uma cadeia de eventos é possível observar o TCA como uma resposta dos países amazônicos à tentativa de ingerência do Centro pela internacionalização da região amazônica. Essa resposta, entendida como um processo, tem como mecanismo causal a situação de desenvolvimento e subdesenvolvimento dos países que formam a região amazônica.

A Tabela 2 consta os níveis de análise que abrangem o TCA. O nível internacional, foco desse trabalho, foi abordado na primeira seção e tem a Conferência de Bandung como condição suficiente e Conferência de Estocolmo como condição necessária para o surgimento do TCA. Em que pese essas condições, observa-se agora brevemente os níveis regionais e doméstico brasileiro para a formação do TCA.

Tabela 2: Níveis de análise do TCA.

\begin{tabular}{ll}
\hline Internacional & Conferências de Bandung, 1955 \\
& Conferência de Estocolmo, 1972 \\
Regional & Tratado de Cooperação Amazônica, 1978 \\
Doméstico & Desenvolvimento amazônico, 1970-1980
\end{tabular}

Fonte: Elaboração própria (2018)

Revista Brasileira de Políticas Públicas e Internacionais, v.3, n.2, Dezembro/2018, pp. 100-124. 
MESQUITA, Murilo; LINHARES, M. de M.; VASCONCELOS, L. M. B.; ARAÚJO, B. M. A Economia Política Internacional e a Agenda Ambiental: como o tratado de cooperação amazônico está inserido na relação centro-periferia?

Na história da América Latina um projeto civilizatório foi imposto a partir do processo de expansão do capitalismo. Nesse projeto, estruturas de opressão e subordinação foram desenvolvidas e impostas a partir de uma relação de alteridade etnocêntrica que silenciou todo um continente. Esse processo de silenciamento geopolítico, que configura as relações internacionais, tem como parâmetro a colonialidade do poder, uma vez que impõe um sentimento de inferioridade aos povos cujas “perspectivas não contam” (Mignolo, 2007, p. 17).

O exercício dessa colonialidade do poder é observado na Conferência da ONU sobre o Meio Ambiente de 1972. Nessa conferência, o Centro adotou uma postura preservacionista, segundo a qual os recursos naturais encontrados na Periferia não poderiam ser usados para exploração. O discurso adotado por eles [o Centro] era de que a defesa da preservação ambiental era uma forma de impedir o crescimento econômico dos países menos desenvolvidos, mantendo assim a estrutura econômica global” (Roman, 1998, p. 15 apud Antiquera, 2006, p. 54).

Nesse imbróglio, os países subdesenvolvidos e em desenvolvimento reivindicaram o reconhecimento do direito ao desenvolvimento e atuaram com uma postura anti-colonialista. É em meio a esse debate que o Brasil detém um papel fundamental. As décadas de 1960 e 1970 foram marcantes para o crescimento econômico brasileiro, o que permitiu uma maior ocupação a partir da interiorização do território nacional. Marcos para esse período são (i) a transferência da capital brasileira para Brasília-DF; (ii) a adoção de políticas de incentivos fiscais; (iii) a criação da Superintendência de Desenvolvimento da Amazônia (SUDAM); e criação do eixo Belém-Brasília, com a revitalização de Manaus com a Zona Franca (Ricupero, 1984; Silva, 2013).

Concomitante à essa pujança econômica brasileira, observa-se na região que os países circunvizinhos também presenciaram um momento de dinamismo, como a exploração do petróleo no Peru, Equador e Colômbia; a pecuária na Bolívia; a siderurgia na Venezuela (Ricupero, 1984). Apesar disso, não foi o fator econômico que promoveu a articulação entre esses Estados, mas sim uma leitura geopolítica do cenário que fez emergir uma relativa insurgência aos interesses do Centro para a região amazônica (Silva, 2013). Dentro desta, o Brasil detém um papel relevante na crítica à defesa do Centro pelo preservacionismo (Spektor, 2004). A posição brasileira, então, sustentava que o discurso do Centro se configurava como um ato de ingerência nos interesses da Periferia e um ato de ingerência na região de países soberanos (Antiquera, 2006; Silva, 2013).

Revista Brasileira de Políticas Públicas e Internacionais, v.3, n.2, Dezembro/2018, pp. 100-124. 
MESQUITA, Murilo; LINHARES, M. de M.; VASCONCELOS, L. M. B.; ARAÚJO, B. M. A Economia Política Internacional e a Agenda Ambiental: como o tratado de cooperação amazônico está inserido na relação centro-periferia?

Assim, desde a criação do Comitê Intergovernamental para a Proteção e o Manejo da Flora e da Fauna Amazônicas - instituído por Brasil, Bolívia, Colômbia, Equador, Peru e Venezuela, em 1975 (Nunes, 2016) -, discussões em torno de temas regionais favoreceram a ascensão de um sentimento e uma agenda pan-amazônica, que foram instrumentalizados pelo governo brasileiro. Em março de 1977, em meio a governos militares, o Brasil consultou os demais países amazônicos sobre a viabilidade de um acordo regional. Depois de observada a recepção unânime e positiva, a diplomacia brasileira apresenta aos países uma anteproposta do que viria a ser o TCA (Ricupero, 1984; Nunes, 2016).

Ao longo de três reuniões entre os Estados-membros, na última, em Caracas, em 3 de julho de 1978, é instituído o Tratado de Cooperação Amazônica, cujos signatários foram o Brasil, Bolívia, Colômbia, Equador, Guiana, Peru, Venezuela e Suriname (Ricupero, 1984; Lessa, 1997; Antiquera, 2006; Nunes, 2016). “Durante o processo de negociação, sempre predominou entre todos os países um clima de harmoniosa colaboração e de construtiva participação” (Ricupero, 1984, p. 185).

Essa proposta brasileira de cooperação se deu no âmbito de uma integração física dos países da região em torno de dois objetivos centrais: (i) facilitar o acesso à região amazônica, e (ii) construir uma identidade latino-americana contrária à ingerência estrangeira (Antiquera, 2006). Em ambos os objetivos é possível observar a construção de um papel de projeção e influência que o Brasil busca submeter à região norte do subcontinente. "Pela primeira vez, o Brasil teve uma política definida para a Amazônia” (Ricupero, 1984, p. 179).

Essa análise é observada a partir do exame do discurso de 1978 do então presidente Ernesto Geisel (1974-1979), durante a cerimônia de assinatura do Tratado. Nesse trabalho, o exame é feito de duas maneiras: na primeira, como observado na Tabela 3, através de um método de análise do discurso, com a associação entre os objetivos centrais do TCA e a fala de Geisel. Assim, é possível observar a relação entre os dois níveis de análise, o regional e o doméstico.

Revista Brasileira de Políticas Públicas e Internacionais, v.3, n.2, Dezembro/2018, pp. 100-124. 
MESQUITA, Murilo; LINHARES, M. de M.; VASCONCELOS, L. M. B.; ARAÚJO, B. M. A Economia Política Internacional e a Agenda Ambiental: como o tratado de cooperação amazônico está inserido na relação centro-periferia?

Tabela 3: Objetivos do TCA e o Discurso brasileiro

\begin{tabular}{ll}
\hline Objetivos & Discurso \\
(i) Facilitar o acesso à região amazônica & “a Amazônia é, ainda, uma região por \\
& descobrir” (GEISEL, 1978, p. 125) \\
& "Prioridade, ao menos igual, se deverá \\
& conceder ao intercâmbio de experiências em \\
& matéria de desenvolvimento regional” \\
& (GEISEL, 1978, p. 125) \\
& “Aperfeiçoar as condições de navegabilidade, \\
& construir portos e armazéns, levar avante \\
& estudos hidrológicos e de clima” (GEISEL, \\
& 1978, p. 125) \\
& “deve-se começar a pensar no planejamento \\
& integrado de uma infra-estrutura de transportes \\
& e telecomunicações” (GEISEL, 1978, p. 125)
\end{tabular}

(ii) Construir uma identidade latino-americana “desenha-se, nítido, o contorno de um movimento que nasce com a vocação, não de abolir ou suplantar os demais esboços de integração latino-americana, mas de complementá-los” (GEISEL, 1978, p. 1978, p. 127)

Fonte: Elaboração própria (2018)

Na segunda, o exame é feito a partir de uma análise de conteúdo. Para realiza-la utiliza-se o software livre IRAMUTEQ versão 0.7 alpha 2, com o qual o TCA e discurso de Geisel são operacionalizados. Com o Iramuteq extrai-se a frequência de palavras, numa nuvem de cada corpus (Figura 1) e uma análise de similitude (Figura 2), entre o TCA e o discurso de Geisel.

Figura 1: Nuvem de Palavras do TCA

Revista Brasileira de Políticas Públicas e Internacionais, v.3, n.2, Dezembro/2018, pp. 100-124. 
MESQUITA, Murilo; LINHARES, M. de M.; VASCONCELOS, L. M. B.; ARAÚJO, B. M. A Economia Política Internacional e a Agenda Ambiental: como o tratado de cooperação amazônico está inserido na relação centro-periferia?

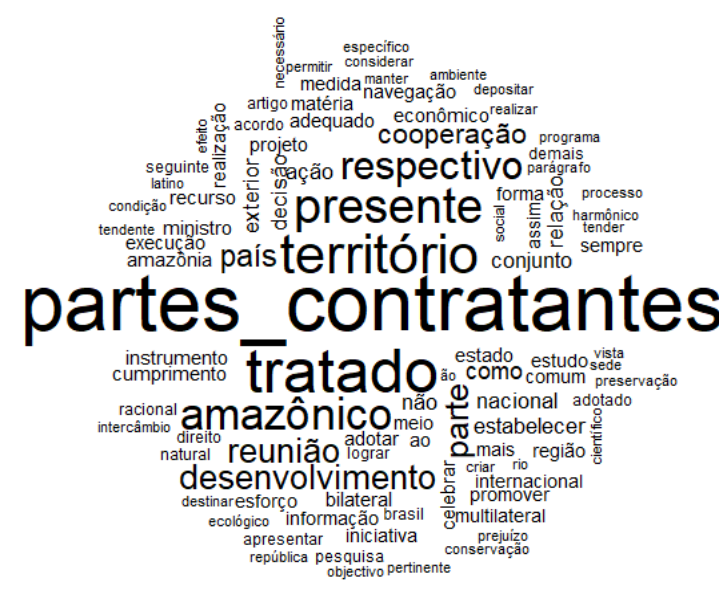

Fonte: Elaboração própria (2018)

Figura 2: Nuvem de Palavras do Discurso de Geisel

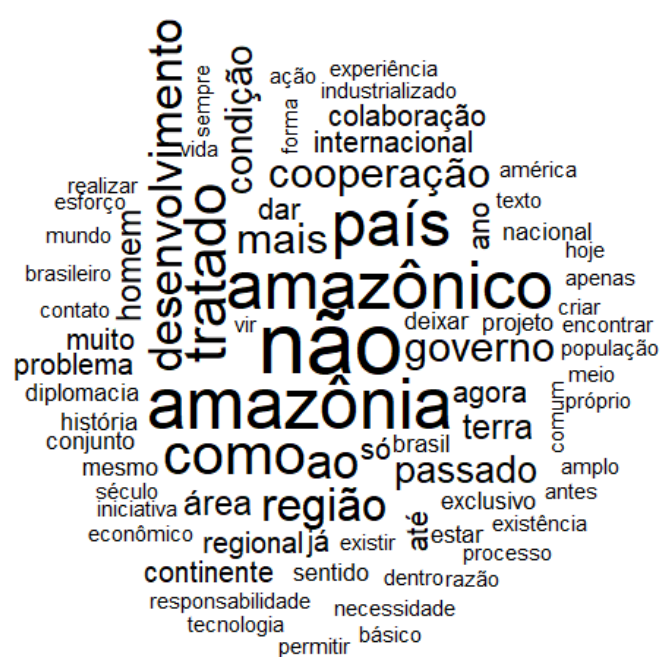

Fonte: Elaboração própria (2018)

Revista Brasileira de Políticas Públicas e Internacionais, v.3, n.2, Dezembro/2018, pp. 100-124. 
MESQUITA, Murilo; LINHARES, M. de M.; VASCONCELOS, L. M. B.; ARAÚJO, B. M. A Economia Política Internacional e a Agenda Ambiental: como o tratado de cooperação amazônico está inserido na relação centro-periferia?

Figura 3: Similitude de Palavras entre o TCA e o discurso de Geisel

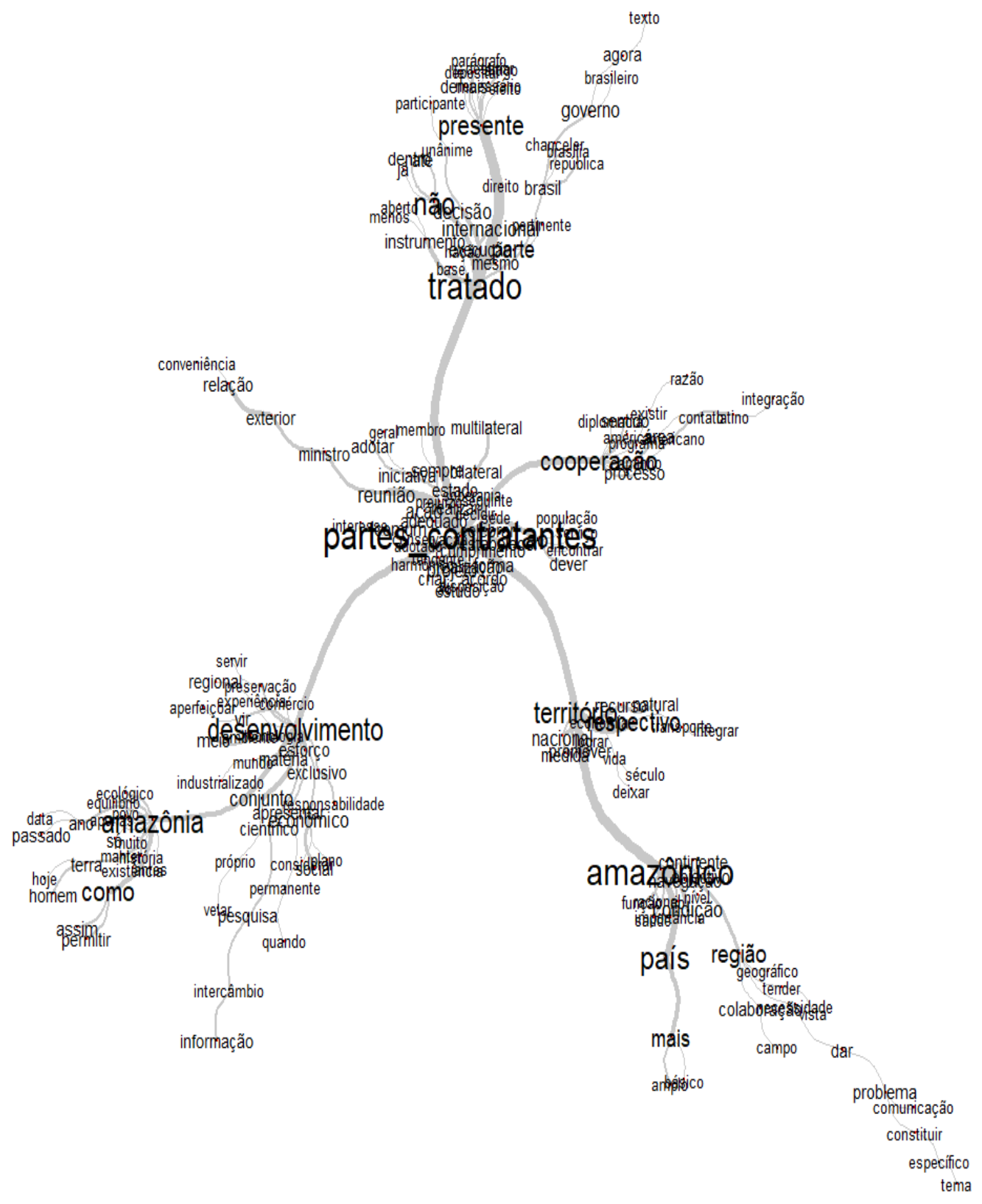

Fonte: Elaboração própria (2018)

Revista Brasileira de Políticas Públicas e Internacionais, v.3, n.2, Dezembro/2018, pp. 100-124. 
MESQUITA, Murilo; LINHARES, M. de M.; VASCONCELOS, L. M. B.; ARAÚJO, B. M. A Economia Política Internacional e a Agenda Ambiental: como o tratado de cooperação amazônico está inserido na relação centro-periferia?

A partir da análise da Figura 1 e Figura 2, observa-se que o discurso de Geisel está fortemente associado com os objetivos do Tratado. Na figura 1, referente aos termos do Tratado, as cinco maiores frequências foram "Partes Contratantes”, Tratado”, “Território”, “Presente”, “Amazônico”. Na figura 2, referente ao discurso de Geisel, a figura apresenta as seguintes cinco maiores frequências com pertinência ao objeto são “Não”, “Amazônia”, “Amazônico”, "País” e “Tratado”.

A Figura 3, por sua vez, faz uma análise de similitude, por meio da qual o corpus é mobilizado de forma a identificar a associação entre os dados. Como um "bolsa de palavras" (GRIMMER e STEWART, 2013), observa-se sua correspondência. Da análise é possível notar que os termos são centralizados nos Estados-membros (Partes Contratantes) através dos quais, termos como “tratado”, “cooperação”, “desenvolvimento” e “amazônico” são salientes.

Não obstante esse resultado, compreender o TCA é associá-lo a uma conjuntura específica que permitiu o Brasil jogar a política internacional. Nesse sentido, observa-se que o resultado encontrado na análise dos dados é parte complementar às condições necessárias e/ou suficientes, pertinentes ao contexto da década de 1970, que fornecem uma consistência causal para o estabelecimento do TCA em 1978 a partir do papel desempenhado pelo Brasil.

Essas condições são estabelecidas conforme a Figura 3 com o Diagrama causal.

Revista Brasileira de Políticas Públicas e Internacionais, v.3, n.2, Dezembro/2018, pp. 100-124. 




Fonte: Elaboração própria (2018)

Assim, a perda de consistência da estratificação internacional, quando o poder relativo das principais potências cede lugar à emergência de países localizados na semiPeriferia e Periferia do sistema, pode ser colocada como o primeiro fator facilitador à construção do Tratado (Lima \& Moura, 1982; Lessa, 1997). Essa distensão favoreceu a alteração no eixo das relações internacionais, de Leste-Oeste para Norte-Sul, e ao Brasil, um movimento na esfera internacional, com a Diplomacia do Interesse Nacional, pautado em concepções de poder e na sua aplicação em órgãos decisórios (Vizentini, 2008; Cervo \& Bueno, 2010).

É nesse contexto que a atuação do Brasil, sob o Governo Geisel (1974-1979) e com o Chanceler Azeredo da Silveira, é orquestrada. Executa-se uma política externa denominada Pragmatismo Ecumênico e Responsável (Lima \& Moura, 1982; Lessa, 1997; Spektor, 2004), através da qual, o Brasil é projetado a uma instância de maior complexidade.

\footnotetext{
${ }^{2}$ Da leitura do diagrama observa-se que a (i) Conferência de Bandung é condição suficiente que, além de ensejar o debate (ii) Centro-Periferia, provoca a (iii) Conferência de Estocolmo. Nessa conferência a conjuntura de (iv) distensão da Guerra Fria provoca (ii) uma (v) alteração no eixo das relações internacionais, de Leste-Oeste para Norte-Sul; além da (vi) abertura da agenda política internacional para a inserção da temática ambiental. Nesse ínterim cria-se o (vii) Comitê Intergovernamental para a Proteção e o Manejo da Flora e da Fauna Amazônicas, quando a diplomacia brasileira consulta os Estados membros para a (vii) formulação do TCA. No lançamento do tratado, o (viii) Geisel postula em seu discurso a base da sua política externa, do (ix) Pragmatismo Ecumênico e Responsável. Dentro desse discurso é possível observar um (x) contorno identitário que pode ser observado como uma (xi) resposta à relação centro-periferia.
} 
MESQUITA, Murilo; LINHARES, M. de M.; VASCONCELOS, L. M. B.; ARAÚJO, B. M. A Economia Política Internacional e a Agenda Ambiental: como o tratado de cooperação amazônico está inserido na relação centro-periferia?

A partir da instrumentalização dessa política externa, o Brasil conseguiu (i) jogar num contexto marcado pela assimetria de poder entre o Centro e a Periferia; (ii) usufruir do momento de esfriamento do conflito político ideológico da Guerra Fria; (iii) apresentar-se como um Estado revisionista (Spektor, 2004); e (iv) projetar a pauta ambiental como um tema de autodeterminação e soberania.

Essa pauta propiciou ao Brasil uma posição de destaque, já que estava a frente de um projeto que reivindicava soberania sobre os recursos naturais, proteção ambiental e desenvolvimento econômico sustentável. Nesses termos, “o pragmatismo responsável foi uma incubadora bastante apropriada para o surgimento do TCA” (Antiquera, 2006, p. 51).

Nesse sentido, a construção do TCA pode ser observada como uma resposta ao acirramento das relações entre o Centro e Periferia, observado desde a Conferência de Bandung, em 1995, mas intensificada na Conferência de Estocolmo, em 1972. Deste modo, ao invés de um Tratado em torno do recrudescimento infra-estrutural da região, o que se viu foi a defesa enfática de um viés regionalista e a reivindicação de uma identidade latinoamericana que podem ser observados no próprio tratado.

No preâmbulo do Tratado consta: “a cooperação entre as nações latino-americanas em matérias específicas que lhe são comuns contribui para avançar no caminho da integração e solidariedade de toda a América Latina” (Tratado de Cooperação Amazônico, 1978). Além disso, é possível observar a confirmação do embate Centro-Periferia e a reivindicação do Espírito de Bandung.

Na Tabela 4 estão ordenados os três princípios do Espírito de Bandung e os artigos do TCA que podem ser associados.

Tabela 4: A relação Princípios do TCA e Espírito de Bandung

Princípios

(i) Não-alinhamento
Artigos do TCA

Art. I: “As Partes Contratantes convêm em realizar esforços e ações conjuntas a fim de promover o desenvolvimento harmônico de seus respectivos territórios amazônicos, de

Revista Brasileira de Políticas Públicas e Internacionais, v.3, n.2, Dezembro/2018, pp. 100-124. 
MESQUITA, Murilo; LINHARES, M. de M.; VASCONCELOS, L. M. B.; ARAÚJO, B. M. A Economia Política Internacional e a Agenda Ambiental: como o tratado de cooperação amazônico está inserido na relação centro-periferia?

modo a que essas ações conjuntas produzam resultados equitativos e mutuamente proveitosos, assim como para a preservação do meio ambiente e a conservação e utilização racional dos recursos naturais desses territórios.”;

Art. XIII: “As Partes contratantes cooperarão para incrementar as correntes turísticas, nacionais e de terceiros países, em seus respectivos territórios amazônicos, sem prejuízo das disposições nacionais de proteção às culturas indígenas e aos recursos naturais”;

(ii) Eliminação de todas as formas de racismoArt. IV: “As Partes Contratantes proclamam e colonialismo que o uso e aproveitamento exclusivo dos recursos naturais em seus respectivos territórios é direito inerente à soberania do Estado e seu exercício não terá outras restrições senão as que resultem do Direito Internacional.”;

(iii) Modernização e o desenvolvimentoArt. $\mathrm{I}^{3}$

sustentável dos países do “Terceiro Mundo”. Art. V: “Tendo em vista a importância e multiplicidade de funções que os rios amazônicos desempenham no processo de desenvolvimento econômico social da região, as Partes Contratantes procurarão envidar esforços com vistas à utilização racional dos recursos hídricos";

Art. VII: "Tendo em vista a necessidade de

\footnotetext{
${ }^{3}$ Optou-se por não repetir aqui o que consta no Art. I.
}

Revista Brasileira de Políticas Públicas e Internacionais, v.3, n.2, Dezembro/2018, pp. 100-124. 
MESQUITA, Murilo; LINHARES, M. de M.; VASCONCELOS, L. M. B.; ARAÚJO, B. M. A Economia Política Internacional e a Agenda Ambiental: como o tratado de cooperação amazônico está inserido na relação centro-periferia?

que o aproveitamento da flora e da fauna da Amazônia seja racionalmente planejado, a fim de manter o equilíbrio ecológico da região e preservar as espécies";

Art. XIII ${ }^{4}$

Fonte: Elaboração própria (2017)

Com essa análise do Tratado, observa-se a construção de uma identidade latinoamericana, periférica e terceiro-mundista que possibilitou a cooperação entre os países da região. Essa cooperação, muito mais que uma questão técnica, vinculada à modernização da Amazônia, teve uma expressão política contra a ingerência dos interesses do Centro numa região rica em recursos naturais. Segundo Ricupero (1984), o Tratado teve um efeito de intensificar os contatos internacionais entre países que praticamente se ignoravam mutuamente.

Observar o TCA dessa forma é compreender que apesar da estrutura do sistema internacional ser pautada numa relação hierárquica e etnocêntrica do sistema CentroPeriferia, é possível à Periferia ler a si própria, de modo a construir uma identidade e um pensamento orgânico, autêntico e periférico (Mignolo apud Castro-Gomez, 2005). Nesse sentido, mesmo que a médio prazo o Tratado não tenha tido a eficiência, nem a projeção que pretendeu seus idealizadores, ele pode ser observado como uma resposta às tentativas de ingerência na região, bem como eficiente na projeção de seus objetivos geopolíticos (Silva, 2013).

\section{Considerações Finais}

Como o Tratado de Cooperação Amazônico está inserido na relação CentroPeriferia? Essa foi a pergunta que guiou o desenvolvimento da pesquisa. A partir desse questionamento, desenvolveu-se uma argumentação sobre como está configurada a economia política internacional (EPI), especificamente acerca do desenvolvimento do

\footnotetext{
${ }^{4}$ Optou-se por não repetir aqui o que consta no Art. XIII
}

Revista Brasileira de Políticas Públicas e Internacionais, v.3, n.2, Dezembro/2018, pp. 100-124. 
MESQUITA, Murilo; LINHARES, M. de M.; VASCONCELOS, L. M. B.; ARAÚJO, B. M. A Economia Política Internacional e a Agenda Ambiental: como o tratado de cooperação amazônico está inserido na relação centro-periferia?

capitalismo e suas consequências para a questão ambiental, notadamente para a região da Amazônia e para os Estados que a formam.

Em que pese o desenvolvimento da pesquisa, foi possível observar que em meados das décadas de 1970 e 1980 houve a necessidade de uma nova agenda para os estudos de EPI. Essa agenda teve como pauta as questões ambientais e de desenvolvimento sustentável. A partir dessa inserção foi possível estabelecer uma ligação entre economia política internacional, meio ambiente e cooperação.

A junção entre EPI, meio ambiente e políticas de cooperação, foi estabelecida, $a$ priori, a partir da barganha pelo desenvolvimento sustentável. Nesse sentido, esse desenvolvimento sustentável passou a ser incorporado às discussões e fóruns de política internacional como uma pauta para além das fronteiras nacionais, por isso, um tema transnacional.

Essa incorporação, no entanto, ocorreu a partir de relações assimétricas entre o Centro e a Periferia. A partir dessas discussões e com o objetivo de garantir os interesses dos países do Centro, os fóruns internacionais, notadamente a Conferência de Estocolmo, marcada pelo embate Norte-Sul, buscaram impedir a Periferia do seu direito ao desenvolvimento econômico e à posse sobre os recursos naturais.

Dessa forma, o que se viu foram fóruns marcados por uma característica colonialista. Nesse contexto, a pesquisa observou que a construção do TCA se deu como uma resposta à tentativa de ingerência por parte dos Estados do Centro para controlar os recursos naturais da Periferia. Nesse sentido, o TCA pode ser observado como um instrumento institucional para garantir o controle sobre a Amazônia contra a sua internacionalização promovida pelo Centro.

Por isso, o Tratado de Cooperação Amazônico também se apresenta como um instrumento de defesa da soberania nacional dos países signatários. Nesse sentido, a construção do Tratado pode ser observada à luz das relações Centro-Periferia do sistema internacional. E, ao fim e ao cabo, é possível denotar que o mesmo foi uma resposta conjunta dos países da região da Amazônia, notadamente do Brasil, às assimetrias dessa relação.

Revista Brasileira de Políticas Públicas e Internacionais, v.3, n.2, Dezembro/2018, pp. 100-124. 
MESQUITA, Murilo; LINHARES, M. de M.; VASCONCELOS, L. M. B.; ARAÚJO, B. M. A Economia Política Internacional e a Agenda Ambiental: como o tratado de cooperação amazônico está inserido na relação centro-periferia?

\section{REFERÊNCIAS}

Antiquera, D. (2006). O Tratado De Cooperação Amazônica. In: A Amazônia e a Política Externa Brasileira: análise do Tratado de Cooperação Amazônico e sua transformação em Organização Internacional (1978-2002). Dissertação. Programa de Pós-Graduação San Tiago Dantas - IFCH - Unicamp.

Castro-Gómez, S. (2005). La Hybris del Punto Cero: ciencia, raza e ilustración en la Nueva Granada (1750-1816). Bogotá: Editorial Pontifícia Universidad Javeriana.

Cervo, A. \& Bueno, C. (2010). Meios e Resultados do Pragmatismo em Política Externa (1967-1979). In: História da Política Exterior do Brasil. Brasília: ed. UnB.

Chasek, P., Downie, D. \& Brown, J. (2013). Global Environment Politics. Colorado: Westview Press.

Clapp, J. \& Helleiner, E. (2012). International Political Economy and the Environment: back to the basics? International Affairs, $n^{\circ}$ 88, vol. 3, pp. 485-501. Disponível em: < https://doi.org/10.1111/j.1468-2346.2012.01085.x> Acesso em: 10 de jul de 2017.

Der Pijl, K. V. (2015). Global political economy and the separation of academic disciplines. In: Fouskas, V. The Politics of International Political Economy: a survey. Nova York: Routledge.

Harris, P.G. Introduction: delineating global environmental politics. (2014). In: Harris, P. (org). Routledge Handbook of Global Environments Politics. Londres e Nova York: Routledge.

Held, D. \& Mcgrew, A. (2001). Conceituando Globalização. In: Prós e Contra da Globalização. Rio de Janeiro: Zahar.

Hunt, E.K; Lautsenheiser, M. (2013). História do Pensamento Econômico: uma perspectiva crítica. Rio de Janeiro: Elsevier, 2013.

Final Communiqué Of The Asian-African Conference (2009). Interventions: International Journal of Postcolonial Studies, Vol. 11, $\mathrm{n}^{\circ}$ 1, pp. 94-102. DOI: $10.1080 / 13698010902752830$

Furtado, C. (2009). Desenvolvimento e Subdesenvolvimento. Rio de Janeiro: Contraponto, 2009.

Revista Brasileira de Políticas Públicas e Internacionais, v.3, n.2, Dezembro/2018, pp. 100-124. 
MESQUITA, Murilo; LINHARES, M. de M.; VASCONCELOS, L. M. B.; ARAÚJO, B. M. A Economia Política Internacional e a Agenda Ambiental: como o tratado de cooperação amazônico está inserido na relação centro-periferia?

Geisel, E. (1978). Uma Nova Amazônia para Encontro e Colaboração entre os Povos da América. Discurso de assinatura do Tratado de Cooperação Amazônico. Disponível em: <www.scielo.br/pdf/aa/v8n2/1809-4392-aa-8-2-0123.pdf. > Acesso em: 26 de out de 2017.

Gilpin, R. (2002) A Dinâmica da Economia Política Internacional. In: A Economia Política das Relações Internacionais. Brasília, Ed. UnB.

Grosfoguel, R. (2006). World-Systems Analysis in the Context of Transmodernity, Border Thinking, and Global Coloniality. Review Postcolonial Studies to Decolonial Studies: Decolonizing Postcolonial Studies (Fernand Braudel Center), vol. 29, $\mathrm{n}^{\circ}$ 2, p. 167-187. Disponível em: < http://www.jstor.org/stable/40241659> Acesso em 01/07/2017.

Joshi, S. (2014). North-South relations: Colonialism, empire and international order. In: Harris, P. (org). Routledge Handbook of Global Environments Politics. Londres e Nova York: Routledge, 2014.

Kochtcheeva, L. V. (2014). Globalization and the environment: markets, finance and trade. In: HARRIS, Paul (org). Routledge Handbook of Global Environments Politics. Londres e Nova York: Routledge, pp. 284-295.

Lessa, A. C. (1997). Instabilidade e Mudanças: os condicionantes históricos da política externa brasileira sob Geisel (1974-1979). Revista de Informação Legislativa, n 34, vol. 133. Disponível em: <https://www2.senado.leg.br/bdsf/bitstream/handle/id/196/r13308.PDF?sequence $=4>$ Acesso em: 26 de out de 2017.

Lima, M, R. S. \& Moura, G. (1982). A trajetória do pragmatismo: uma análise da política externa brasileira. Dados, vol. 25, $\mathrm{n}^{0}$ 3, pp. 349-64. Disponível em: <https://edisciplinas.usp.br/mod/resource/view.php?id=64387> Acesso: 26 de out de 2017.

Löwy, M. (2013). Crise Ecológica, Crise Capitalista, Crise De Civilização: A Alternativa Ecossocialista. CADERNO CRH, Salvador, v. 26, 67, pp. 79-86. Disponível em:

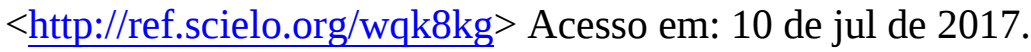

Mignolo, W. (2007). Separar las Palabras de las Cosas. In: La Idea de América Latina: a la herida colonial y la opción decolonial. Barcelona: Ed. Gedisa.

Nesadurai, H. (2005). Bandung and the Political Economy of North-South relations: sowing the seeds for revisioning international society. Working Paper 95. Nanyang, Singapura: Institute of Defense and Strategic Studies. Disponível em: $<$ http://www.rsis.edu.sg/publications/WorkingPapers/WP95.pdf $>$ Acesso em: 10 de jul de 2017.

Nunes. P. H. F. (2016). A organização do tratado de cooperação amazônica: uma análise crítica das razões por trás da sua criação e evolução. Brasília. Revista de Direito Internacional, vol. 13, $\mathrm{n}^{\mathrm{o}} \quad 2, \quad$ pp. 220-243. Disponível em: <

Revista Brasileira de Políticas Públicas e Internacionais, v.3, n.2, Dezembro/2018, pp. 100-124. 
MESQUITA, Murilo; LINHARES, M. de M.; VASCONCELOS, L. M. B.; ARAÚJO, B. M. A Economia Política Internacional e a Agenda Ambiental: como o tratado de cooperação amazônico está inserido na relação centro-periferia?

https://www.publicacoesacademicas.uniceub.br/rdi/article/download/4037/pdf > . Acesso em: 01 de jul de 2017.

Oliveira, I. T. M. (2007). A Ordem Econômico-Comercial internacional: Uma Analise da evolução do Sistema Multilateral de comércio. Contexto Internacional, Rio de Janeiro, vol. 29, no 2, pp. 217-272. Disponível em: <http://www.scielo.br/pdf/cint/v29n2/v29n2a01.pdf> Acesso em: 13 de abr de 2017.

Quijano, A. (2000). Coloniality of Power, Eurocentrism, and Latin America. Nepantla: views from South. 2000. Disponível em: <http://www.unc.edu/ aescobar/wan/wanquijano.pdf> Acesso em: 01 de jul de 2017.

Ricupero, R. (1984). O Tratado de Cooperação Amazônica. Revista de Informação Legislativa, Brasília, vol. 21, $\mathrm{n}^{\circ}$ 81. Disponível em: <https://www2.senado.leg.br/bdsf/bitstream/handle/id/186318/000406292.pdf?sequence=1>

Rodriguez, O. (2009). A Concepção do Sistema Centro-Periferia. In: O Estruturalismo Latino-Americano. Rio de Janeiro: Civilização Brasileira.

Santos, M. (2001). Por uma Outra Globalização: do pensamento único à consequência universal. Rio de Janeiro: Record.

Santos, T. S. (2001). Globalização e Exclusão: a dialética da mundialização do capital. Sociologias, Porto Alegre, ano 3, $\mathrm{n}^{0}$ 6, pp. 170-198. Disponível em: <http://www.scielo.br/pdf/soc/n6/a08n6.pdf> . Acesso em: 01 de jul de 2017.

Silva, R. I. (2013). O Multilateralismo Amazônico, entre Êxitos Geopolíticos e Entraves Executivos: trajetória do processo de cooperação de 1978 a 2012. Brazilian Journal of International Relations, vol. 2, $\mathrm{n}^{\mathrm{o}}$ 3, Disponível em: <http://www2.marilia.unesp.br/revistas/index.php/bjir/article/view/3053>

Spektor, M. (2004). Origens e Direção do Pragmatismo Ecumênico e Responsável (19741979). Revista Brasileira de Política Internacional, $\mathrm{n}^{\circ}$ 47, vol 2, pp.191-222. Disponível em: <http://www.scielo.br/scielo.php?script=sci_arttext\&pid=S0034-73292004000200007> Acesso em: 01 de jul de 2017.

Streeck, W. (2016). Introduction. How Will Capitalism End? In: How Will Capitalism End? Londres e Nova York: Verso.

Tratado de Cooperação Amazônica. (1978). Disponível em: <http://otca.info/portal/admin/_upload/tratado/O_TRATADO_DE_COOPERACAO_AMA ZONICA_PT.pdf>. Acesso em: 10 de jul de 2017.

Revista Brasileira de Políticas Públicas e Internacionais, v.3, n.2, Dezembro/2018, pp. 100-124. 
MESQUITA, Murilo; LINHARES, M. de M.; VASCONCELOS, L. M. B.; ARAÚJO, B. M. A Economia Política Internacional e a Agenda Ambiental: como o tratado de cooperação amazônico está inserido na relação centro-periferia?

Vizentini, P. F. (2008). O "Brasil Potência”: segurança, desenvolvimento e autonomia no regime militar (1964-1979). In: Relações Internacionais do Brasil: de Vargas a Lula. São Paulo: Ed. Perseu Abramo.

Wallerstein, I. (1974). Dependence in an Interdependent World: The Limited Possibilities of Transformation within the Capitalist World Economy. African Studies Review, vol. 17, $\mathrm{n}^{\circ}$ 1, pp. 1-26. Disponível em: <http://www.jstor.org/stable/523574 >. Acesso em: 02 de jul de 2017.

Revista Brasileira de Políticas Públicas e Internacionais, v.3, n.2, Dezembro/2018, pp. 100-124. 